\title{
The Science Transfer Series: Technology transfer from academia to industry and its impact on university management
}

\author{
Marli Elizabeth Ritter dos Santos \\ Coordinator of the Technology Transfer Office of the Pontifical Catholic University of Rio Grande do Sul (PUCRS) \\ Past President of FORTEC - Fórum Nacional de Gestores de Inovação e Transferência de Tecnologia \\ (The National Forum of Innovation and Technology Transfer Managers) \\ E-mail: elizabeth.ritter@pucrs.br
}

$I_{\text {no }}^{n}$ n a knowledge society, the economic and social power of countries depends on their capacity to generate, use, and spread scientific and technological knowledge. In this context, universities play a central role, incorporating into their traditional functions of teaching and research those of economic and social development, characterized as their "third mission" (1).

To assure their performance in this third mission, universities have established technology transfer offices, with the goal of facilitating the spread of academic research results, by means of licensing the intellectual property assets to industry.

In the United States, the country considered to be the pioneer of these measures, academic technology transfer was fundamentally impacted by the University and Small Business Patent Procedures Act of 1980, known internationally as the Bayh-Dole Act.

The Bayh-Dole Act created incentives for technology transfer from academia to industry, simplifying this process by means of a uniform policy of patenting and the removal of various licensing restrictions, resulting in a significant impact on the performance of American universities, in terms of the number of patents filed and granted, signed licenses, spin-off companies created, jobs created, and the amount earned through royalties.

While these results may be considered important, it is above all the social relevance of these activities developed in universities, that presents the largest impact. In 2001, the National Institute of Health (NIH) prepared a report called the Wyden Report, which analyzes the impact of federal resources on biomedical research and the return on investment. Despite criticizing several aspects of the Bayh-Dole Act, the report recognizes that the fomenting of scientific discovery, the intangible benefits of rapid technological development, and the certainty of access to those products by those who need them are benefits that are "so significant that they exceed the considerations of monetary return" (2).

As such, the Bayh-Dole Act and its subsequent amendments have supplied the foundation for technology transfer practices in universities that have spread worldwide, having been adopted by the majority of countries and only differing according to the environment in which the responsible authors find themselves regarding this activity.

In addition to policies that are aimed at directly stimulating innovation and improving the links between science and industry, it is essential to provide appropriate structural conditions, which include tangible factors, such as financial infrastructure and human resources, as well as intangible factors, such as an entrepreneurial and innovative culture, political institutions, or even the judicial security of having these policies put into practice. In this context, intellectual property rights play an important role, leading to an increased concern for more active management of this matter and a greater institutionalization of the activities of technology transfer offices (3).

In Brazil, only recently has this topic become incorporated into the science and technology agenda. Towards the end of the 1990s, intellectual property acquired importance on the national stage, particularly after the signing of the TRIPS Accord and the resulting commitments for its implementation by means of national laws. This fact, associated with the implementation of new governmental programs stimulating university-industry partnerships, marked a new stage in the Brazilian context for the promotion of technology innovation.

Since 2001, an increasing number of universities have integrated themselves into the national intellectual property system, spreading the culture of innovation, broadening awareness of the importance of protecting the results of research, and introducing institutional policies of intellectual property and technology transfer. Inserted into these policies is the sharing with researchers the economic benefits earned by institutions through intangible assets licensing.

In the context of these changes, initiatives such as the creation of technology transfer offices, called Technology Innovation Centers (TICs), driven mainly by the implementation of the Law of Technology Innovation (Law n. 10.973/2004) in 
December of 2004, decisively inaugurated a new phase for the treatment of this matter in the entire country.

The commitment of the government to create the conditions required by this legislation have brought about specific actions by the Ministry of Science and Technology, by means of its development agencies, National Scientific and Technological Development Council (CNPq); Brazilian Technology Innovation Agency (FINEP), which are providing financing opportunities by means of their own edicts, stimulating the creation and consolidation of TICs, valuing the protection of knowledge and its transfer for appropriation by the productive sector, and allowing for human resources training for these specific topics.

Because in Brazil the largest amount of research is performed at research institutions, there is a strong stimulus for the patenting and licensing of research results, with the goal of facilitating technology transfer to industry. All of these activities are performed by the TICs, whose number has increased considerably, currently totaling more than $160^{1}$ in the country, thanks to a new environment provided by the new legislation, articulated with government programs for technological stimulation and innovation.

In this new scenario of growing protections for intellectual property, the management of this matter has become essential for universities and other research institutions, which aim to deepen their relations with industry and broaden the social relevance of their research. From this perspective, the TICs now play a predominant role.

Some results can already be perceived. Important advances in the awareness of the importance of intellectual property protection have been made, mainly expressed in the form of an increase in the number of patent applications to both the National Industrial Property Institute (INPI)and patent offices abroad, originating from universities. Regarding patent licensing, although the results may still be slight, an increase of activity can be observed, and better results are necessarily associated with a greater volume of assets, which the group of institutions are incrementally achieving.

The introduction of these matters into the academic routine brings, therefore, new challenges to management. Upon establishing institutional policies to stimulate innovation, which makes intellectual property protection important in the institutional context, a potential conflict is created in the academic culture, which favors publication. Researchers find themselves divided between their individual interest in publishing their research results, as their academic performance has traditionally been evaluated according to the number and quality of their publications, and those of the institutions that protect intellectual property. To minimize the effects of this apparent ambivalence, TICs play the crucial role of informing the academic community on how to reconcile publication and protection, as both of these practices are forms of disclosing research results, differing only in their means and precedence.

In addition to the institutional policies to stimulate innovation and the creation of management mechanisms, it is also necessary to invest in professional teams for the management of innovation. This has also been a great bottleneck in the national context, on the one hand, due to a low demand in the market for professionals with this qualification, as only recently have these topics become introduced as university majors. On the other hand, it is due to the difficulty of inserting these professionals into the permanent ranks of personnel, largely because of the low valuation of this activity in the institutional context, the results of the TICs only being obtained in the medium- to long- term (3).

In spite of these difficulties encountered by the universities and the many adjustments that still need to be put into practice to fully obtain the possible benefits, it is necessary to recognize the countless advances that the Innovation Law has provided, stemming from a national regulatory framework and management practices.

The number of joint projects being carried out by companies and universities is increasing, and the major challenges lies in obtaining practical results from $R \& D$ projects, in terms of new products/processes that are placed in the market.

Finally, it is fundamental to recognize that the intensification of technology transfer activities is directly related to the volume and quality of the research performed at universities, which continues to be one of the main missions of academic institutions for the fulfillment of their important role in the spread of knowledge and the broadening of its social relevance.

\section{References}

1. Etzkowitz H. From knowledge flows to the triple helix: the transformation of academic-industry relations in the USA. Ind High Educ 1996; 10:337-70.

2. National Institute of Health. A Plan to ensure taxpayers' interests are protected. [cited on 2001 July 2]. Available at: http://www.nih.gov/ news/0701001 wyden.htm.

3. OCDE - Organização para a Cooperação e o Desenvolvimento Econômico. Turning science into business. Patenting and licensing at public research organizations. Paris, France: OCDE; 2003. 